\title{
Nutritional Status Differentially Alters Cytochrome P450 3A4 (CYP3A4) and Uridine 5'-Diphospho-Glucuronosyltransferase (UGT) Mediated Drug Metabolism: Effect of Short-Term Fasting and High Fat Diet on Midazolam Metabolism
}

\author{
Laureen A. Lammers ${ }^{1} \cdot \operatorname{Roos}_{\text {Achterbergh }}{ }^{2} \cdot$ Johannes A. Romijn $^{2} \cdot \operatorname{Ron}$ A. A. Mathôt ${ }^{1}$
}

Published online: 6 June 2018

(C) The Author(s) 2018

\begin{abstract}
Background and Objectives Previous studies have shown that nutritional status can alter drug metabolism which may result in treatment failure or untoward side effects. This study assesses the effect of two nutritional conditions, short-term fasting, and a short-term high fat diet (HFD) on cytochrome P450 3A4 (CYP3A4) and uridine 5'-diphospho-glucuronosyltransferase (UGT) mediated drug metabolism by studying the pharmacokinetics of midazolam and its main metabolites.

Methods In a randomized-controlled cross-over trial, nine healthy subjects received a single intravenous administration of $0.015 \mathrm{mg} / \mathrm{kg}$ midazolam after: (1) an overnight fast (control); (2) $36 \mathrm{~h}$ of fasting; and (3) an overnight fast after 3 days of a HFD consisting of $500 \mathrm{ml}$ of cream supplemented to their regular diet. Pharmacokinetic parameters were analyzed simultaneously using non-linear mixed-effects modeling.

Results Short-term fasting increased CYP3A4-mediated midazolam clearance by $12 \%(p<0.01)$ and decreased UGT-mediated metabolism apparent 1-OH-midazolam clearance by $13 \%(p<0.01)$ by decreasing the ratio of clearance and the fraction metabolite formed $\left(\Delta \mathrm{CL}_{1-\mathrm{OH}}\right.$ MDZ $\left./ f_{1-\mathrm{OH}-\mathrm{MDZ}}\right)$. Furthermore, short-term fasting decreased apparent clearance of 1-OH-midazolam- $O$-glucuronide
\end{abstract}

Laureen A. Lammers and Roos Achterbergh contributed equally.

Laureen A. Lammers

1.a.tenberg-lammers@amc.uva.nl

1 Department of Hospital Pharmacy, Academic Medical Centre, University of Amsterdam, Meibergdreef 9, 1105 AZ Amsterdam, The Netherlands

2 Department of Medicine, Academic Medical Center, University of Amsterdam, Amsterdam, The Netherlands
(CL 1 -OH-MDZ-glucuronide $\left./\left(f_{1-\mathrm{OH}-\mathrm{MDZ} \text {-glucuronide }} \times f_{1-\mathrm{OH}-\mathrm{MDZ}}\right)\right)$ by $20 \%(p<0.01)$. The HFD did not affect systemic clearance of midazolam or metabolites.

Conclusions Short-term fasting differentially alters midazolam metabolism by increasing CYP3A4-mediated metabolism but by decreasing UGT-mediated metabolism. In contrast, a short-term HFD did not affect systemic clearance of midazolam.

\section{Key Points}

Fasting differentially alters midazolam metabolism by increasing CYP3A4-mediated metabolism but by decreasing UGT-mediated metabolism.

Short-term HFD did not affect phase I (CYP) or phase II (UGT)-mediated midazolam metabolism.

\section{Introduction}

Patients respond differently to drug therapy. This is often due to differences in drug metabolism, and may result in treatment failure, increased side effects, or even toxicity. Factors that contribute to this variability in drug metabolism include genetic, physiologic, pharmacologic, environmental factors, and nutritional status, such as fasting or a high fat diet (HFD) [1].

The previous studies in animals and humans have shown that nutritional status can alter drug metabolism by affecting cytochrome P450 (CYP) enzyme activity [2-7]. 
Furthermore, nutritional status can also affect uridine $5^{\prime}$ diphospho-glucuronosyltransferase (UGT) enzyme activity. For example, UGT expression in mouse liver was increased in obesity and fasting-induced steatosis [8]. Recently, we have demonstrated that short-term fasting modulates CYP-enzyme activity in a non-uniform pattern by increasing systemic clearance of the CYP1A2 probe caffeine and the CYP2D6 probe metoprolol and by decreasing systemic clearance of $S$-warfarin which is a probe for CYP isoform CYP2C9 [6, 9].

CYP and UGT enzyme activity can also be modulated by a HFD. Animal studies have revealed differential effects of hypercaloric HFD on CYP and UGT enzymes [8, 10-12]. Furthermore, Miyauchi et al. have recently shown differences in protein expression levels of both CYP enzymes and UGT enzymes in morbidly obese subjects [13]. In addition, we have shown that a short-term hyper caloric HFD in humans increases exposure to orally administered midazolam and omeprazole which are probe drugs for CYP3A4 and CYP2C19, respectively [7].

Midazolam is primarily $(\approx 95 \%)$ metabolized by CYP3A4 to 1-OH-midazolam which makes the drug a suitable probe for isoform CYP3A4 [14, 15]. A minor part is metabolized to 4-OH-midazolam and to 1,4-OH-midazolam, but, as the percentage of these metabolites excreted in urine is less than $4 \%$, these midazolam elimination pathways are not considered significant $[14,15]$.

After oxidative hydroxylation, the metabolites 1-OHmidazolam and 4-OH-midazolam are glucuronidated by UGT (phase II drug metabolism) to enable urinary excretion [14]. Zhu et al. identified an $O$-linked and an $N$-linked glucuronide conjugate of 1-OH-midazolam of which the formation is catalyzed by different UGT isoforms [16]. The $O$-glucuronide is catalyzed by UGT2B4/2B7, whereas the $N$-glucuronide is catalyzed by UGT1A4 [16]. Since the maximal intrinsic clearance for $O$-glucuronidation was $\sim 9$-fold higher than that for $N$-glucuronidation, the CYP3A4-mediated hydroxylation of midazolam to $1-\mathrm{OH}-$ midazolam followed by UGT2B4/2B7-mediated glucuronidation to 1-OH-midazolam-O-glucuronide represents the major pathway of midazolam metabolism [16]. By studying the pharmacokinetics of the parent compound together with its main metabolites, 1-OH-midazolam, and 1-OH-midazolam- $O$-glucuronide, midazolam may not only serve as a probe for CYP3A4 enzyme activity but also for UGT (UGT1A4, UGT2B4/2B7) enzyme activity.

In our previous studies performed on the effect of shortterm fasting and a short-term HFD, we focused on the parent compound midazolam and demonstrated that shortterm fasting did not affect systemic clearance or bioavailability of the drug [6,9]. The validated analytical method used in our previously reported studies did not include the analysis of midazolam metabolites [17]. In our current study, we used another validated liquid chromatographytandem mass spectrometry (LC-MS/MS) method to determine not only the parent compound midazolam but also its main metabolites 1-OH-midazolam, 4-OH-midazolam, and 1-OH-midazolam- $O$-glucuronide. We assessed the effect of a short-term HFD and short-term fasting on CYP3A4 and UGT-mediated metabolism using intravenously administered midazolam as a probe.

\section{Subjects and Methods}

\subsection{Subjects}

Nine healthy male subjects were included in the trial. Subjects were included when (1) aged 18 years or older; (2) healthy as determined by an experienced physician, and with normal renal and liver function. The following exclusion criteria were applied: (1) major illness in the past 3 months, (2) gastrointestinal disease that may influence drug absorption, (3) abnormal values of the following laboratory parameters: alanine aminotransferase, alkaline phosphatase, aspartate aminotransferase, bilirubin, gammaglutamyl transferase, and creatinine, (4) excessive alcohol intake ( $>3$ units of alcohol per day) or use of alcohol for at least 2 days prior to each study day,(5) drugs of abuse, (6) smokers, (7) strenuous exercise at least 3 days prior to each study day, defined as more than $1 \mathrm{~h}$ of exercise per day, (8) use of prescription or non-prescription drugs, (9) consumption of caffeine containing foods or beverages within 1 day prior to study, and (10) consumption of grapefruit and grapefruit-containing products or starfruit for at least 2 days prior to each study day $[6,9]$.

\subsection{Study Design}

We performed an open-label, randomly assigned crossover intervention study in healthy male subjects. After approval of the protocol (Amendment 2, ABRnr: NL40834.018.12) by the institutional ethics review board, this study was performed at the Academic Medical Center, University of Amsterdam, The Netherlands. Each subject gave informed consent for participation in the study. The study was conducted in accordance with the Declaration of Helsinki.

Each subject received a single intravenous administration of $0.015 \mathrm{mg} / \mathrm{kg}$ midazolam $(5 \mathrm{mg} / \mathrm{ml}, 1 \mathrm{ml}$ ampoules, Roche Nederland BV, Woerden, The Netherlands) at three occasions with wash-out periods of 4 weeks: (1) after an overnight fast (control), (2) after $36 \mathrm{~h}$ of fasting, and (3) after an overnight fast after a 3 day hypercaloric high fat diet (HFD). Subjects were randomly assigned for the order in which they underwent the interventions. In all occasions, 
midazolam was administered at 8:00 AM. Subjects were fasting from 10:00 PM, the preceding evening whilst participating in the control intervention. In the fasting intervention, subjects fasted from 8:00 PM starting two evenings prior to administration of midazolam. This ensured a period of $36 \mathrm{~h}$ of fasting at the time of midazolam administration. The hypercaloric HFD consisted of the subject's own regular diet supplemented with $500 \mathrm{ml}$ cream (1715 kcal, 35\% fat) after dinner for a period of 3 days. Cream was supplemented after dinner to ensure that food intake during the day was not affected.

To standardize their diet, subjects kept a diary containing dietary instructions and were asked to take similar meals during the 3 days before the three visits. Compliance to the study protocol was also assessed by phone calls, text messages, and e-mail contact during the interventions. Furthermore, the following biomarkers were measured at baseline to check adherence to the fasting protocol: glucose, $\beta$-hydroxybutyrate, free fatty acids, and acetoacetate [18]. Since a short-term HFD induces biochemical symptoms of hepatic steatosis, gamma-glutamyl transferase (GGT) and alkaline phosphatase (ALP) were measured as biomarkers for the hypercaloric HFD [10, 19]. Serum alkaline phosphatase levels have shown to increase in obese compared to non-obese subjects [20].

On each of the three occasions, subjects had a standard fluid meal (Nutridrink Compact; Nutricia, Zoetermeer, The Netherlands) at noon. The meal was standardized to prevent differences in caloric intake between the interventions to affect the pharmacokinetics of midazolam. After 04:00 PM, subjects were allowed to consume their habitual diet [6].

\subsection{Blood Sampling and Bioanalysis of Midazolam and Metabolites}

For the estimation of pharmacokinetic parameters, blood samples were collected pre-dose and at 2, 11.5, 15, 29, 41.5, 60, 90, 135, 173, 180, and $195 \mathrm{~min}$ and 3.5, 4, 5, 7, and $9 \mathrm{~h}$ after intravenous administration of midazolam. Plasma was separated by centrifugation and stored at $80{ }^{\circ} \mathrm{C}$ until analysis.

The plasma concentrations of midazolam, 1-OH-midazolam, 1-OH-midazolam-O-glucuronide, and 4-OH-midazolam were determined using a validated liquid chromatography/tandem mass spectrometry (LC-MS/MS) method. Protein precipitation of plasma samples was performed using acetonitrile/methanol (ACN:MeOH), 84: 16 $\mathrm{v} / \mathrm{v} /$. Midazolam and metabolites were then separated through a Thermo Scientific Hypersil GOLD (50 mm $\times$ $2.1 \mathrm{~mm}, 1.9 \mu \mathrm{m})$ column from ThermoFisher Scientific (Waltham, MA, USA). The LC-MS/MS setup comprised an LC-30AD (Shimadzu, Kyoto, Japan) system with CTO-
20AC column oven coupled to a Qtrap 5500 system (ABSciex, Concord, Canada). Analyst ${ }^{\mathrm{TM}}$ 1.6.× (ABSciex, Concord, Canada) was used as software package for controlling the LC-MS/MS system and for data processing. Midazolam-d5 and 1-OH-midazolam-d5 were obtained from Toronto Research Chemicals (TRC, Toronto, Canada), and used as internal standards. The method was validated over a range of 4-1000 $\mathrm{ng} / \mathrm{ml}$ for midazolam, 2-500 ng/ml for 1-OH-midazolam and 4-OH-midazolam, and $8-2000 \mathrm{ng} / \mathrm{ml}$ for $1-\mathrm{OH}$-midazolam- $O$-glucuronide. For each analyte, results below this range were considered as below the limit of quantification (BLOQ). Linearity was $R^{2} \geq 0.995$ for all components. For all analytes, the accuracy was between 98.7 and $106.3 \%$ and the withinand between-run imprecision were $<11 \%$ for the lower limit of quantification and $<4.4 \%$ for the middle level and upper limit of quantification. Furthermore, the mean process efficiency was between 93.2 and $117.4 \%$ and the mean ionization efficiency was $>89 \%$. Samples showed no significant degradation during storage for $96 \mathrm{~h}$ at room temperature.

\subsection{Pharmacogenetic Analysis of CYP3A4 Polymorphisms}

Genomic DNA was isolated from whole blood using a total nucleic acid extraction kit on a MagnaPure LC (Roche Diagnostics GmbH, Penzberg, Germany). Genotyping was performed using predesigned DME Taqman allelic discrimination assays on the Life Technologies Taqman 7500 system. Each assay consisted of two allele-specific minor groove-binding (MGB) probes, labeled with the fluorescent dyes VIC and FAM. Polymerase chain reactions (PCR) were performed in a reaction volume of $10 \mu \mathrm{l}$, containing assay-specific primers, allele-specific Taqman MGB probes, Abgene Absolute QPCR Rox Mix and genomic DNA (20 ng). The thermal profile consists of 40 cycles of denaturation at $95^{\circ} \mathrm{C}$ for $20 \mathrm{~s}$ and annealing at $92^{\circ} \mathrm{C}$ for $3 \mathrm{~s}$ and extension at $60^{\circ} \mathrm{C}$ for $30 \mathrm{~s}$. Genotypes were scored by measuring allele-specific fluorescence using the 7500 software v2.3 for allelic discrimination (Applied Biosystems). For CYP3A4, the following single-nucleotide polymorphisms (SNPs) were tested: $-392 \mathrm{~A}>\mathrm{G} \quad(* 1 \mathrm{~B})$, g. $20230 \mathrm{G}>\mathrm{A} \quad(* 1 \mathrm{G}), \quad 664 \mathrm{~T}>\mathrm{C} \quad(* 2), \quad 1334 \mathrm{~T}>\mathrm{C} \quad(* 3)$, $352 \mathrm{~A}>\mathrm{G}(* 4), 653 \mathrm{G}>\mathrm{C}(* 5), 520 \mathrm{G}>\mathrm{C}(* 10), 1117 \mathrm{C}>\mathrm{T}$ $(* 12), 566 \mathrm{~T}>\mathrm{C}(* 17), 878 \mathrm{~T}>\mathrm{C}(* 18)$, and $\mathrm{g} .15389 \mathrm{C}>\mathrm{T}$ (*22). The absence of investigated SNPs gave the default allele assignment "*1A".

\subsection{Pharmacokinetic Analysis}

The pharmacokinetic data were analyzed using the nonlinear mixed-effects modeling software NONMEM 
(Version 7.2., Icon Development Solutions, Hanover, MD, USA). Software, R [version 64 3.0.1 (The R Foundation for Statistical Computing)] and Xpose version 4, were used to visualize and evaluate the models [21]. Pirana software was used as an interface between NONMEM, R, and Xpose [22].

To adjust concentrations of the metabolites to their midazolam equivalent, concentrations were expressed in micromoles per liter, using the molecular weights of midazolam (325.8 g/mol), 1-OH-midazolam (341.8 g/mol), 4-OH-midazolam $(341.8 \mathrm{~g} / \mathrm{mol})$, and 1-OH-midazolamglucuronide $(517.9 \mathrm{~g} / \mathrm{mol})$. Furthermore, the concentrations were logarithmically transformed. Non-linear mixed-effects compartmental modeling was preferred instead of noncompartmental analysis because of the ability to simultaneously analyze midazolam and its metabolites and because significant differences were observed in the time after midazolam administration until concentrations of midazolam and metabolites were below LOQ and, as a consequence, in the number of metabolite samples below the lower limit of quantification (BLOQ) between control and the $36 \mathrm{~h}$ fasting intervention. For midazolam, the median time until samples were BLOQ after control was 3.1 h (range 2.73-4.83 h) compared to $2.72 \mathrm{~h}$ (range 2.62-3.68 h) after the fasting intervention ( $p=0.1$ ) and $2.82 \mathrm{~h}$ (range 2.70-4.89 h) after the HFD ( $p=0.52)$. For 1-OH-midazolam, the median time until samples were BLOQ after control was $2.73 \mathrm{~h}$ (range $1.80-3.38 \mathrm{~h}$ ) compared to $3.18 \mathrm{~h}$ (range $1.70-4.83 \mathrm{~h}$ ) after the fasting intervention $(p=0.08)$ and $2.73 \mathrm{~h}$ (range $1.87-3.33 \mathrm{~h})$ after the HFD $(p=0.95)$. For $1-\mathrm{OH}-$ midazolam- $O$-glucuronide, the median time until samples were BLOQ after control was $3.08 \mathrm{~h}$ (range 1.85-3.85 h) compared to $3.33 \mathrm{~h}$ (range $2.70-5.70 \mathrm{~h}$ ) after the fasting intervention ( $p=0.04$ ) and $3.03 \mathrm{~h}$ (range 2.71-3.74 h) after the HFD $(p=0.95)$. Because of these differences in the time until concentrations were below LOQ and, as a consequence, differences in the number of BLOQ samples between the interventions, the M3 method suggested by Beal was applied using the Laplacian estimation method with interaction [23].

\subsubsection{Structural Model}

The concentration data were log transformed for all compounds; one, two, and three-compartment models were fitted to the data. The population models were built in a stepwise manner. The following parameters were quantified for the parent compound midazolam: clearance (CL), inter-compartment clearances $\left(\mathrm{Q}_{1}\right.$ and $\left.\mathrm{Q}_{2}\right)$, and volumes of distribution of the central $\left(\mathrm{V}_{1}\right)$ and peripheral compartments $\left(\mathrm{V}_{2}\right.$ and $\left.\mathrm{V}_{3}\right)$. For the metabolites of midazolam, the apparent clearances and volumes of distribution were quantified. For example, the apparent clearance of 1-OHmidazolam is quantified as $\mathrm{CL}_{1-\mathrm{OH}-\mathrm{MDZ}} / f_{1-\mathrm{OH}-\mathrm{MDZ}}$, where
$\mathrm{CL}_{1-\mathrm{OH}-\mathrm{MDZ}}$ represents the clearance of 1-OH-midazolam and $f_{1-\mathrm{OH}-\mathrm{MDZ}}$ the fraction of $1-\mathrm{OH}$-midazolam formed. The apparent clearance of $1-\mathrm{OH}$-midazolam- $O$-glucuronide also depends on the fraction of 1-OH-midazolam formed and can be described as $\mathrm{CL}_{1-\mathrm{OH}-\mathrm{MDZ}-\mathrm{Gluc}} / f_{1-\mathrm{OH}-\mathrm{MDZ}-\mathrm{Gluc}-}$ $\times f_{\text {1-он-мDZ }}$ ), where $\mathrm{CL}_{1-\mathrm{OH}-\mathrm{MDZ} \text {-Gluc }}$ represents the clearance of $1-\mathrm{OH}$-midazolam- $O$-glucuronide and $f_{1-\mathrm{OH}-\mathrm{MDZ}-}$ Gluc the fraction 1-OH-midazolam metabolized to $1-\mathrm{OH}-$ midazolam- $O$-glucuronide.

For all parameters' estimates, inter- and intra-individual variability were assessed assuming a log-normal distribution and using an exponential error model [6, 24]. Residual variability was estimated with an additional error model.

Furthermore, individual areas under the plasma concentration-time curve (AUC) values were obtained by post hoc analysis: a Bayesian analysis to obtain individual pharmacokinetic parameters based on the population pharmacokinetic parameters and the individual observed concentrations. Midazolam exposure $\left(\mathrm{AUC}_{\mathrm{MDZ}}\right)$ depends on the administered intravenous midazolam dose (Dose MDZ and its clearance $\left(\mathrm{CL}_{\mathrm{MDZ}}\right)$ as described by Eq. 1 :

$\mathrm{AUC}_{\mathrm{MDZ}}=$ Dose $_{\mathrm{MDZ}} / \mathrm{CL}_{\mathrm{MDZ}}$

The exposure to midazolam metabolites [AUC $(m)$ ] depends on the fraction of metabolite formed $(f(m))$, the administered dose of midazolam (Dose $\mathrm{MDZ}_{\text {), and the total }}$ clearance of the metabolite $(\mathrm{CL}(m))$ as given by the following equations:

For 1-OH-Midazolam (Eq. 2):

$$
\begin{gathered}
\mathrm{AUC}_{1-\mathrm{OH}-\mathrm{MDZ}}=\left(f_{1-\mathrm{OH}-\mathrm{MDZ}} \times \text { Dose }_{\mathrm{MDZ}}\right) \\
/ \mathrm{CL}_{1-\mathrm{OH}-\mathrm{MDZ}}
\end{gathered}
$$

For 1-OH-Midazolam-O-Glucuronide (Eq. 3):

$$
\begin{aligned}
& \mathrm{AUC}_{1-\mathrm{OH}-\mathrm{MDZ}-\text { Glucuronide }} \\
& \quad=\left(f_{1-\mathrm{OH}-\mathrm{MDZ}} \times f_{1-\mathrm{OH}-\mathrm{MDZ}-\text { Glucuronide }} \times \text { Dose }_{\mathrm{MDZ}}\right) \\
& \quad / \mathrm{CL}_{1-\mathrm{OH}-\mathrm{MDZ}-\text { glucuronide }}
\end{aligned}
$$

The log-likelihood ratio test was used to discriminate between different structural and statistical models. A reduction in the objective function value $(\mathrm{OFV}) \geq 3.84$ points was considered as statistically significant $(p<0.05$ for one degree of freedom) [24]. In addition, goodness-offit (GOF) plots (population or individual predictions versus observations of measured drug concentrations, and conditional weighted residuals (CWRES) versus time and population predictions and $\eta$ - and $\varepsilon$-shrinkage) were assessed [25]. Furthermore, the confidence interval of the parameter estimates, the correlation matrix, and visual improvement of the individual plots were used to evaluate the model. Ill-conditioning was assessed by the ratio 
between the largest and smallest eigenvalues of the covariance matrix of the estimate from the NONMEM output. A ratio of $>1000$ indicates ill-conditioning of the model and is often due to over-parameterization [26].

\subsubsection{Covariate analysis}

The effects of short-term fasting and a short-term hypercaloric HFD on pharmacokinetic parameters of midazolam and metabolites were evaluated by stepwise inclusion in the models [27]. For example, the effect of short-term fasting on clearance was evaluated using the following power function (Eq. 4):

$\mathrm{CL}_{i}=\mathrm{CL}_{\text {pop }} \times \theta_{\text {fasting }}$

where $\theta_{\text {fasting }}$ is the fractional change of clearance due to fasting [6]. The effect of either fasting or HFD was tested for one pharmacokinetic parameter at a time and statistically tested by the likelihood ratio test. When fasting or HFD significantly affected more than one parameter, the model with the largest decrease in the OFV was chosen as basis to sequentially explore the influence of additional parameters. The final model containing the effects of fasting and HFD was further evaluated as discussed in the structural model section.

\subsubsection{Model Validation}

To evaluate validity and robustness of the final models, simulation-based diagnostics (visual predictive checks) and bootstrap diagnostics were used [28, 29]. The bootstrap analysis was performed using the Perl modules Pearlspeaks-NONMEM. The model-building data set was resampled 1000 times to create new data sets similar in size $[28,30]$. Parameter estimates obtained by the bootstrap analysis (median values and the 2.5th and 97.5th percentiles of parameter distribution) were compared with the parameter estimates of the final pharmacokinetic models. Visual predictive check (VPC) plots were used to compare the 10th and 90th percentiles of simulated concentrationtime profiles (1000 replicates) with the observed concentrations [29].

\subsection{Statistical Analysis}

Paired $t$ tests (normally distributed data) and Wilcoxon signed-rank tests (not normally distributed data) were used to test differences in biochemical parameters between the occasions. The Shapiro-Wilk test was used to assess the normality of data distribution. A $p$ value $\leq 0.05$ was considered significant. Statistical analysis was performed using IBM SPSS Statistics version 23.0.

\section{Results}

Nine healthy male subjects (mean age 24 years) were recruited to participate in the trial. No adverse events were reported. A summary of the baseline characteristics is shown in Table 1. There were no significant changes in body weight at baseline for each treatment period.

DNA for the analysis of CYP3A4 polymorphisms was available in seven subjects. Subjects were screened for 11 SNPs of CYP3A4, but no polymorphisms were detected. Therefore, all seven subjects were characterized as extensive metabolizers $\left(\mathrm{EM}, * 1 \mathrm{~A} /{ }^{*} 1 \mathrm{~A}\right)$ with normal CYP3A4 enzyme activity (Table 1).

After $36 \mathrm{~h}$ of fasting, the biomarkers for fasting (glucose, $\beta$-hydroxybutyrate, free fatty acids, and acetoacetate) were all significantly altered in comparison with control (Table 1). After a short-term hypercaloric HFD alkaline, phosphatase levels significantly increased from $63 \mathrm{U} / \mathrm{L}$ (range 48-90) (control) to $73 \mathrm{U} / \mathrm{L}$ (range 45-95) $(p=0.017)($ Table 1).

\subsection{Pharmacokinetics of midazolam and metabolites}

The plasma concentrations-versus-time profiles of midazolam and metabolites were best described using a threecompartment model for midazolam and a one-compartment model for both 1-OH-midazolam and 1-OH-midazolam- $O$-glucuronide (Fig. 1). 4-OH-midazolam could not be included in the model, since no concentrations could be measured in any of the subjects $(<\mathrm{LLOQ}$, lower limit of quantification). In the three-compartment model of midazolam, the first and second peripheral volumes of midazolam were equalized to obtain a stable model. Interoccasion variability (IOV) on midazolam clearance significantly improved the model in terms of OFV and goodness-of-fit plots but resulted in over-parameterization. Therefore, it was not further incorporated within the model.

\subsubsection{Effect of Short-Term Fasting and a Short-Term Hypercaloric HFD on Midazolam Metabolism}

3.1.1.1 Midazolam The systemic clearance of midazolam $\left(\mathrm{CL}_{\mathrm{MDZ}}\right)$ was $27.3 \mathrm{~L} / \mathrm{h}$ (95\% confidence interval (CI) 24.4-29.2) for the typical subject. Short-term fasting significantly increased $\mathrm{CL}_{\mathrm{MDZ}}$ by $12 \%\left(\theta_{\mathrm{CL}}\right.$ Fasting $=1.12$, 95\% CI 1.05-1.19, $p<0.01$ ), (Table 2). A short-term hypercaloric HFD did not alter systemic clearance of midazolam: $\theta_{\mathrm{CL}}$ High Fat $=1.05$, 95\% CI $0.93-1.17$, $p>0.05$ ), (Table 2). These effects may also be appreciated in the visual predictive check plots, Fig. 2A1-A4. Individual areas under the plasma concentration-time curve 
Table 1 Baseline characteristics and effect of $36 \mathrm{~h}$ of fasting or a high fat diet versus control on biochemical parameters in healthy subjects $(n=9)$

\begin{tabular}{|c|c|c|c|c|c|c|}
\hline Parameter & $\begin{array}{l}\text { Value } \\
\text { Median (range) }\end{array}$ & $\begin{array}{l}\text { Control } \\
\text { Median (range) }\end{array}$ & $\begin{array}{l}\text { Fasting ( } 36 \mathrm{~h}) \\
\text { Median (range) }\end{array}$ & $p$ value & $\begin{array}{l}\text { High fat diet } \\
\text { Median (range) }\end{array}$ & $p$ value \\
\hline Age (years) & $24(19-33)$ & & & & & \\
\hline Height $(\mathrm{cm})$ & $185(175-194)$ & & & & & \\
\hline Body weight (kg) & $80(68-103)$ & & & & & \\
\hline Genotype $(n=7)$ & $N$ & & & & & \\
\hline CYP3A4 & 7 & & & & & \\
\hline \multicolumn{7}{|l|}{$* 1 \mathrm{~A} / * 1 \mathrm{~A}(\mathrm{EM})$} \\
\hline Glucose (mmol/L) & & $4.97(4.40-5.40)$ & $4.40(3.60-5.00)$ & 0.024 & $5.13(4.60-5.70)$ & 0.261 \\
\hline$\beta$-hydroxybutyrate (mmol/L) & & $0.10(0.00-0.20)$ & $0.83(0.30-2.70)$ & 0.011 & $0.09(0.00-0.20)$ & 0.701 \\
\hline Acetoacetate $(\mathrm{mmol} / \mathrm{L})$ & & $0.05(0.01-0.09)$ & $0.25(0.06-0.80)$ & 0.012 & $0.04(0.01-0.06)$ & 0.176 \\
\hline Free fatty acids $(\mathrm{mmol} / \mathrm{L})$ & & $0.48(0.19-0.73)$ & $1.29(0.63-2.57)$ & 0.012 & $0.39(0.15-0.90)$ & 0.398 \\
\hline Alkaline Phosphatase (U/L) & & $63(48-90)$ & $65(51-77)$ & 0.440 & $73(45-95)$ & 0.017 \\
\hline$\gamma$-glutamyl transferase (U/L) & & $13.3(9.00-21.0)$ & $14.6(7.00-22.0)$ & 0.157 & $18.4(8.00-36.0)$ & 0.108 \\
\hline Serum creatinine $(\mu \mathrm{mol} / \mathrm{L})$ & & $74(62-97)$ & $82(67-100)$ & 0.065 & $76(62-89)$ & 0.440 \\
\hline Serum albumin $(\mathrm{g} / \mathrm{L})$ & & $47(44-49)$ & $48(45-51)$ & 0.256 & $47(46-49)$ & 0.726 \\
\hline
\end{tabular}

CYP cytochrome P450, EM extensive metabolizer

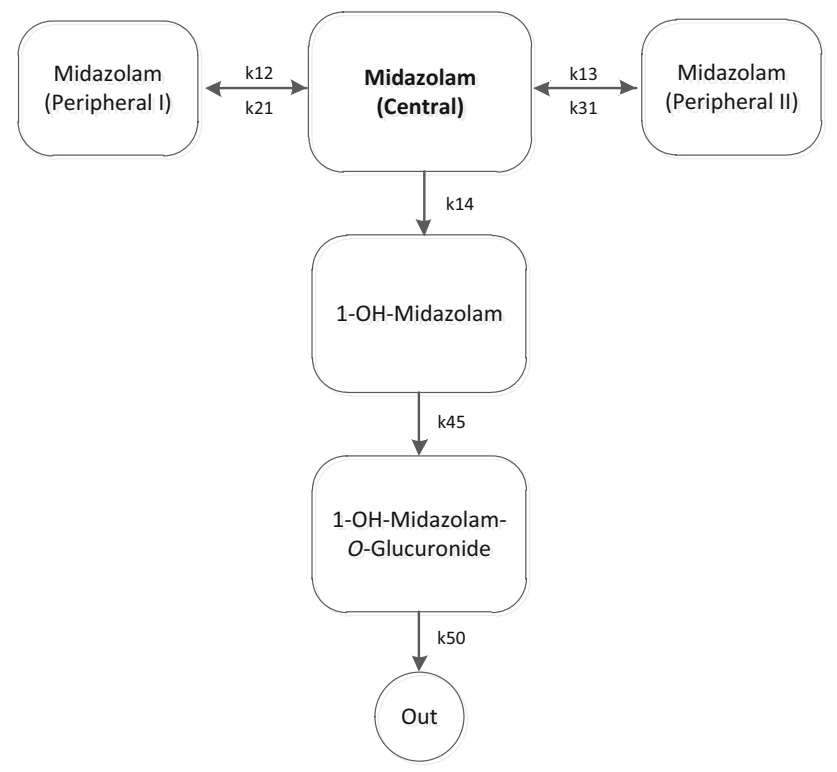

Fig. 1 Schematic illustration of the pharmacokinetic model of midazolam and metabolites 1-hydroxy-midazolam (1-OH-midazolam) and 1-hydroxy-midazolam- $O$-glucuronide (1-OH-midazolam- $O$ glucuronide). $\mathrm{kmn}$ represents the rate constant between compartment number $m$ and compartment number $n$ (e.g., $\mathrm{k} 12$ is the rate constant between the central compartment of midazolam and its first peripheral compartment; $\mathrm{k} 21$ is vice versa). $\mathrm{k} 50$ represents the elimination rate constant of 1-OH-midazolam- $O$-glucuronide

(AUC) values were obtained by post hoc analysis. Midazolam exposure was decreased after short-term fasting: the median midazolam area under the plasma concentrationtime curve $\left(\mathrm{AUC}_{\text {midazolam }}\right)$ was $0.132 \mu \mathrm{mol} / \mathrm{L} \cdot \mathrm{h}$ (range $0.110-0.214)$ in the control group and $0.118 \mu \mathrm{mol} / \mathrm{L} \cdot \mathrm{h}$ (range 0.098-0.190) after short-term fasting (Fig. 3). Exposure after short-term HFD was $0.126 \mu \mathrm{mol} / \mathrm{L} \cdot \mathrm{h}$ (range 0.105-0.203) (Fig. 3).

3.1.1.2 1-OH-Midazolam Short-term fasting significantly decreased the apparent 1-OH-midazolam clearance $\left(\mathrm{CL}_{1-}\right.$ OH-MDZ $\left./ f_{1-\mathrm{OH}-\mathrm{MDZ}}\right)$ by $13 \%\left(\theta_{\mathrm{CL}}\right.$, Fasting $=0.87,95 \% \mathrm{CI}$ $0.80-0.95, p<0.01$ ) (Table 2). Short-term hyper caloric HFD did not alter apparent 1-OH-midazolam clearance $\left(\theta_{\mathrm{CL}}, \quad\right.$ High $\quad$ Fat $=1.04, \quad 95 \%$ CI $\left.0.92-1.16, \quad p>0.05\right)$ (Table 2). These effects may also be appreciated in the visual predictive check plots, Fig. 2b1-4. Post hoc AUC 1 OH-MDZ increased from $0.033 \mu \mathrm{mol} / \mathrm{L} \cdot \mathrm{h}$ (range $0.028-0.039)$ in the control group to $0.038 \mu \mathrm{mol} / \mathrm{L} \cdot \mathrm{h}$ (range 0.032-0.045) after short-term fasting (Fig. 3). After a short-term hypercaloric HFD, the median $\mathrm{AUC}_{1-\mathrm{OH}-\mathrm{MDZ}}$ was $0.032 \mu \mathrm{mol} / \mathrm{L} \cdot \mathrm{h}$ (range $0.027-0.038$ ) (Fig. 3).

3.1.1.3 1-OH-Midazolam-O-Glucuronide The apparent clearance of $1-\mathrm{OH}$-midazolam- $O$-glucuronide $\left[\mathrm{CL}_{1-\mathrm{OH}}\right.$ MDZ-glucuronide $\left./\left(f_{1-\mathrm{OH}-\mathrm{MDZ} \text {-glucuronide }} * f_{1-\mathrm{OH}-\mathrm{MDZ}}\right)\right]$ for the typical subject was $38.9 \mathrm{~L} / \mathrm{h}$ [95\% confidence interval (CI): 31.8-46.0]. Short-term fasting significantly decreased $\mathrm{CL}_{1}$ OH-MDZ-glucuronide $/\left(f_{1 \text {-OH-MDZ-glucuronide }} * f_{1 \text {-OH-MDZ }}\right)$ by $20 \%$ $\left(\theta_{\mathrm{CL}, \text { Fasting }}=0.80,95 \% \mathrm{CI} 0.68-0.93, p<0.01\right)($ Table 2$)$. Short-term hyper caloric HFD did not alter apparent 1-OHmidazolam- $O$-glucuronide clearance $\left(\theta_{\mathrm{CL}}\right.$ High Fat $=0.97$, 95\% CI 0.85-1.10, $p>0.05$ ) (Table 2). Post hoc $\mathrm{AUC}_{1-}$ OH-MDZ-glucuronide increased from $0.091 \mu \mathrm{mol} / \mathrm{L} \cdot \mathrm{h}$ (range $0.072-0.119)$ in the control group to $0.113 \mu \mathrm{mol} / \mathrm{L} \cdot \mathrm{h}$ 
(range 0.089-0.148) after $36 \mathrm{~h}$ of fasting (Fig. 3). After a short-term HFD, the median $\mathrm{AUC}_{1-\mathrm{OH}-\mathrm{MDZ} \text {-glucuronide was }}$ $0.093 \mu \mathrm{mol} / \mathrm{L} \cdot \mathrm{h}$ (range 0.074-0.122) (Fig. 3). These effects may also be appreciated in the visual predictive check plots, Fig. 2C1-4.

\subsubsection{Model validation}

The observed data were described well by the developed models as demonstrated by the goodness-of-fit plots (Fig. 4a (midazolam), b (1-OH-midazolam), and c (1-OH-midazolam- $O$-glucuronide). Furthermore, no trends were observed in the plots of conditional weighted residuals versus time (CWRES) or model predicted concentrations (plots not shown). The $\eta$ and $\varepsilon$ shrinkage of the pharmacokinetic parameters and residual variability were $<20 \%$. The bootstrap analysis ( $n=1000$ replicates) confirmed the results of the model (Table 2). In addition, the visual predictive check (VPC) plots demonstrate good agreement between the observed data and the model simulated confidence intervals for the median, 10th and 90th percentiles (Fig. 2).

\section{Discussion}

In this cross-over intervention study in healthy subjects, we determined the effects of short-term fasting and a shortterm hypercaloric HFD on CYP3A4 and UGT-mediated
Fig. 2 Visual predictive check plots of midazolam and metabolites. Midazolam: panels a1-a4, 1-OH-midazolam: panels b1-b4, 1-OHmidazolam- $O$-glucuronide: panels c1-c4. Panels 1: the solid $(36 \mathrm{~h}$ fasting), striped (high fat diet), and dashed (control) lines represent the 10th and 90th percentiles of the simulated data. Panels 2: open circles represent the control observations. The dashed (control) lines represent the 10th and 90th percentiles of the simulated data. BLOQ concentrations are fixed to $\mathrm{LOQ} / 2$. Panels 3 : open circles represent the observed data points after $36 \mathrm{~h}$ of fasting. The solid ( $36 \mathrm{~h}$ fasting) lines represent the 10th and 90th percentiles of the simulated data. BLOQ concentrations are fixed to $L O Q / 2$. Panels 4: open circles represent the observed data points after a high fat diet. The striped (high fat diet) lines represent the 10th and 90th percentiles of the simulated data. BLOQ concentrations are fixed to $\mathrm{LOQ} / 2$. BLOQ below the limit of quantification

metabolism of midazolam. We found that short-term fasting increased systemic clearance of midazolam, thereby decreasing the exposure to the parent compound midazolam. This indicates that fasting increased the activity of CYP3A4, considering that midazolam is primarily metabolized to 1-OH-midazolam by CYP3A4. Furthermore, short-term fasting decreased the apparent clearances of 1-OH-midazolam and 1-OH-midazolam- $O$-glucuronide, thereby increasing the exposure to both metabolites. In contrast, a HFD did not affect midazolam metabolism.

The maximum effect of fasting on enzyme activity is expected when a new steady-state level of the affected enzyme has been obtained [31]. This is dependent on the rate of enzyme turnover and on the time needed to reach a

Table 2 Pharmacokinetic (PK) parameters of midazolam and metabolites in nine healthy male subjects and mean parameter values (2.5-97.5\%) of non-parametric bootstrap replicates of the final PK model

\begin{tabular}{|c|c|c|c|c|c|c|}
\hline \multirow[b]{2}{*}{ Parameters } & \multicolumn{2}{|l|}{ Midazolam (MDZ) } & \multicolumn{2}{|c|}{ 1-OH-Midazolam (1-OH-MDZ) } & \multicolumn{2}{|c|}{$\begin{array}{l}\text { 1-OH-Midazolam- } O \text {-Glucuronide (1- } \\
\text { OH-MDZ-Glc) }\end{array}$} \\
\hline & $\begin{array}{l}\text { Estimates } \\
\text { Typical value (95\% } \\
\text { CI) }\end{array}$ & $\begin{array}{l}\text { Bootstrap } \\
\text { Median } \\
\quad(2.5-97.5 \%)\end{array}$ & $\begin{array}{l}\text { Estimates } \\
\text { Typical value (95\% } \\
\text { CI) }\end{array}$ & $\begin{array}{l}\text { Bootstrap } \\
\text { Median } \\
\quad(2.5-97.5 \%)\end{array}$ & $\begin{array}{l}\text { Estimates } \\
\text { Typical value (95\% } \\
\text { CI) }\end{array}$ & $\begin{array}{l}\text { Bootstrap } \\
\text { Median } \\
\quad(2.5-97.5 \%)\end{array}$ \\
\hline $\mathrm{CL}(\mathrm{L} / \mathrm{h})$ & $27.3(24.4-29.2)$ & $27.4(25.1-29.9)$ & $112(90.6-133)$ & $115(91.9-138)$ & $38.9(31.8-46.0)$ & $39.5(32.9-46.7)$ \\
\hline$\theta_{\mathrm{Cl} 36 \mathrm{~h} \text { fasting }}$ & $1.12(1.05-1.19)$ & $1.12(1.06-1.22)$ & $0.87(0.80-0.95)$ & $0.87(0.79-0.94)$ & $0.80(0.68-0.93)$ & $0.80(0.68-0.94)$ \\
\hline$\theta_{\mathrm{Cl} \text { high fat diet }}$ & $1.05(0.93-1.17)$ & $1.06(0.94-1.17)$ & $1.04(0.92-1.16)$ & $1.03(0.93-1.15)$ & $0.97(0.85-1.10)$ & $0.98(0.86-1.11)$ \\
\hline $\mathrm{V}_{1}(\mathrm{~L})$ & $18.1(15.0-21.2)$ & $17.4(10.6-20.1)$ & $87.1(69.9-104)$ & $89.1(72.5-112)$ & $5.60(4.84-6.36)$ & $5.58(4.68-6.58)$ \\
\hline $\mathrm{Q}(\mathrm{L} / \mathrm{h})$ & $68.5(26.4-110)$ & $66.4(51.3-158)$ & - & - & - & - \\
\hline $\mathrm{V}_{2}(\mathrm{~L})$ & $24.3(20.4-28.2)$ & $23.9(20.4-28.8)$ & - & - & - & - \\
\hline $\mathrm{Q}_{2}(\mathrm{~L} / \mathrm{h})$ & $9.55(3.30-15.8)$ & $10.4(5.69-21.1)$ & - & - & - & - \\
\hline $\mathrm{V}_{3}(\mathrm{~L})$ & $24.3(20.4-28.2)$ & $23.9(20.4-28.8)$ & - & - & - & - \\
\hline \multicolumn{7}{|c|}{ Inter-individual variability } \\
\hline $\mathrm{CL}(\%)$ & $14.9(11.9-17.9)$ & $13.3(7.51-18.7)$ & $18.2(16.0-20.4)$ & $16.5(9.40-21.1)$ & $23.4(20.6-26.2)$ & $22.1(14.5-28.8)$ \\
\hline \multicolumn{7}{|c|}{ Residual variability } \\
\hline $\begin{array}{l}\text { Additional } \\
\text { error }\end{array}$ & $0.24(0.21-0.27)$ & $0.23(0.19-0.26)$ & $0.21(0.13-0.29)$ & $0.21(0.15-0.28)$ & $0.18(0.15-0.21)$ & $0.18(0.14-0.21)$ \\
\hline
\end{tabular}

Bold represents statistically significant values

$C L$ clearance, $Q$ inter-compartment clearance, $V_{1}$ volume of distribution of the central compartment, $V_{2}$ volume of distribution of the first peripheral compartment, $V_{3}$ volume of distribution of the second peripheral compartment, $\theta$ difference in PK parameter 

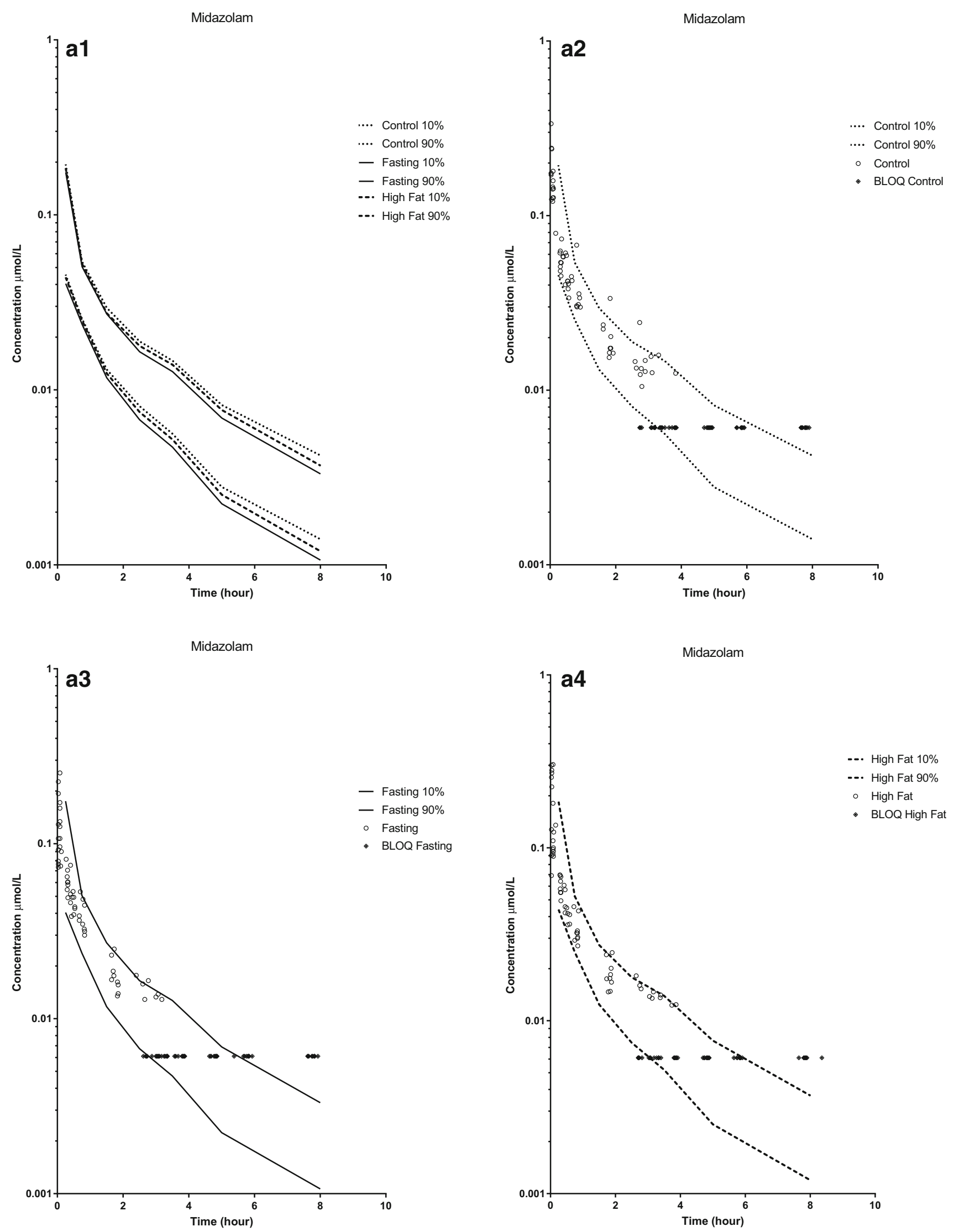
1-OH-Midazolam

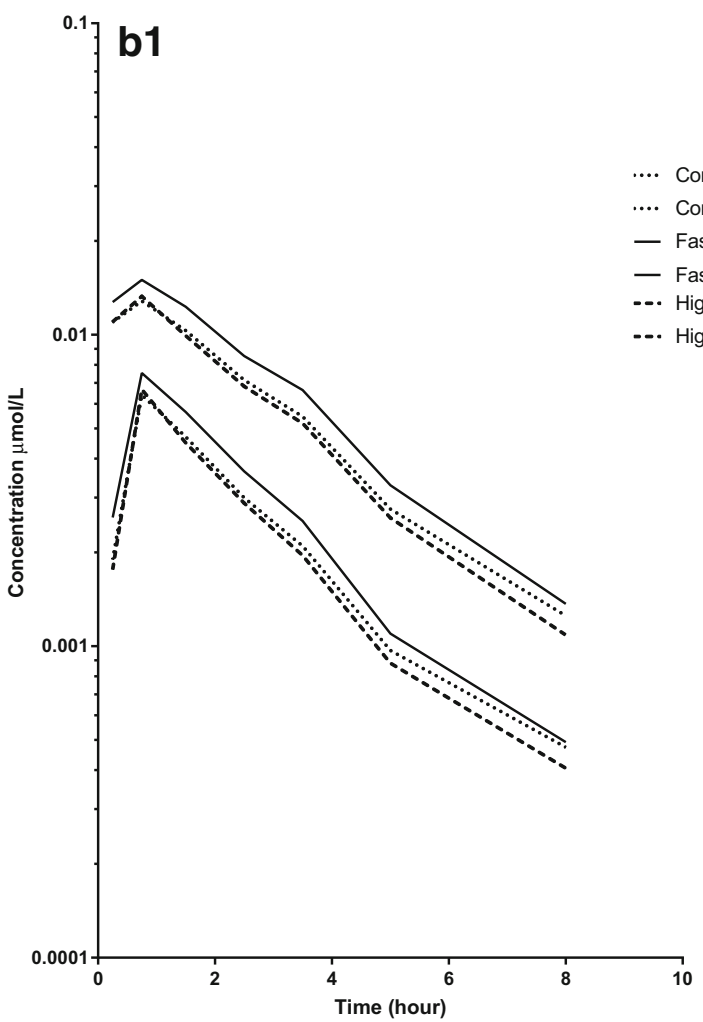

1-OH-Midazolam

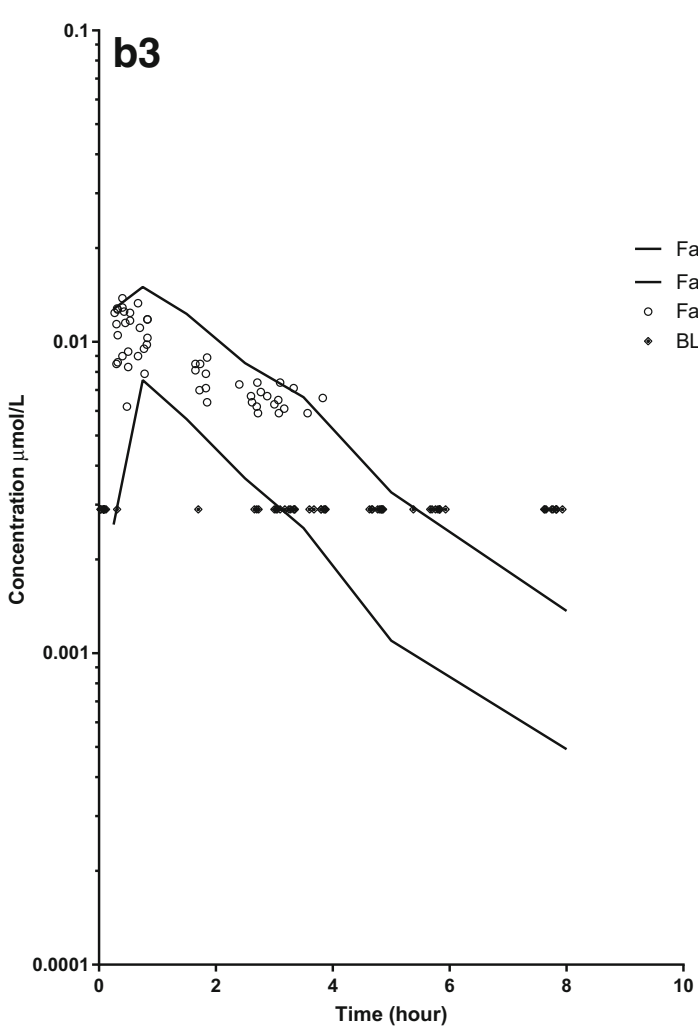

1-OH-Midazolam
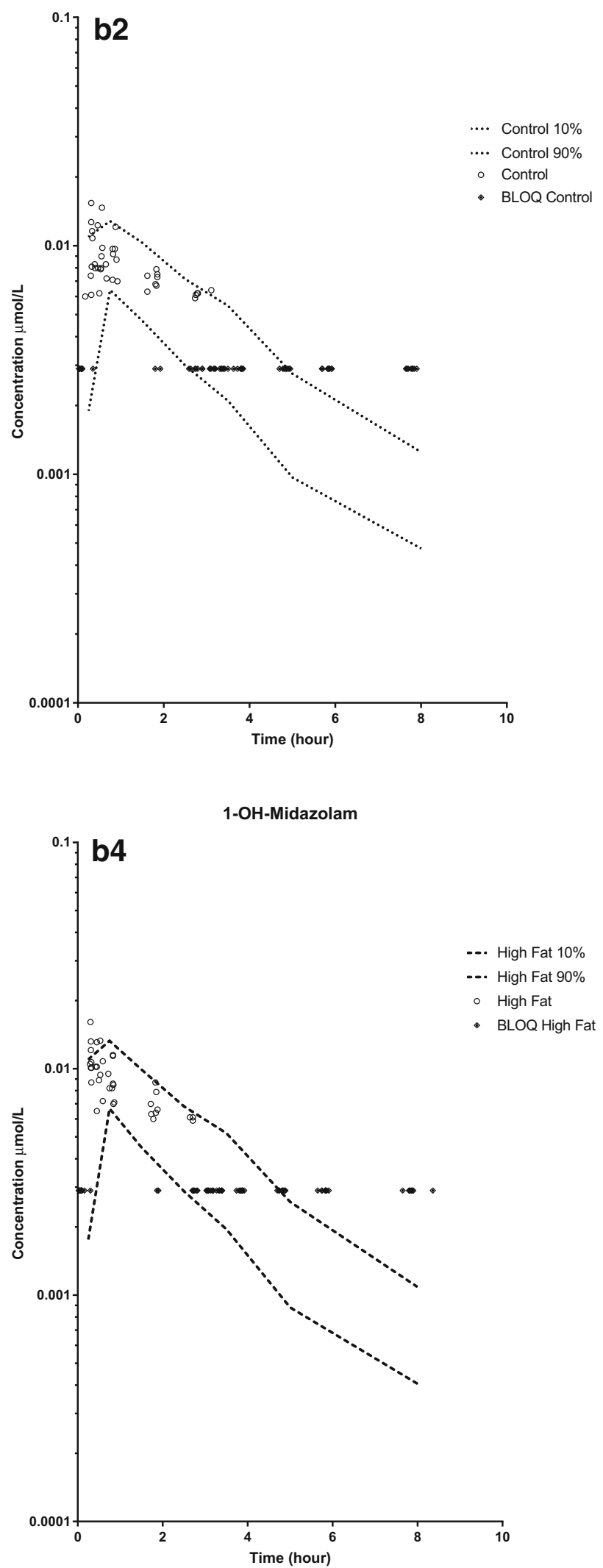

Fig. 2 continued 

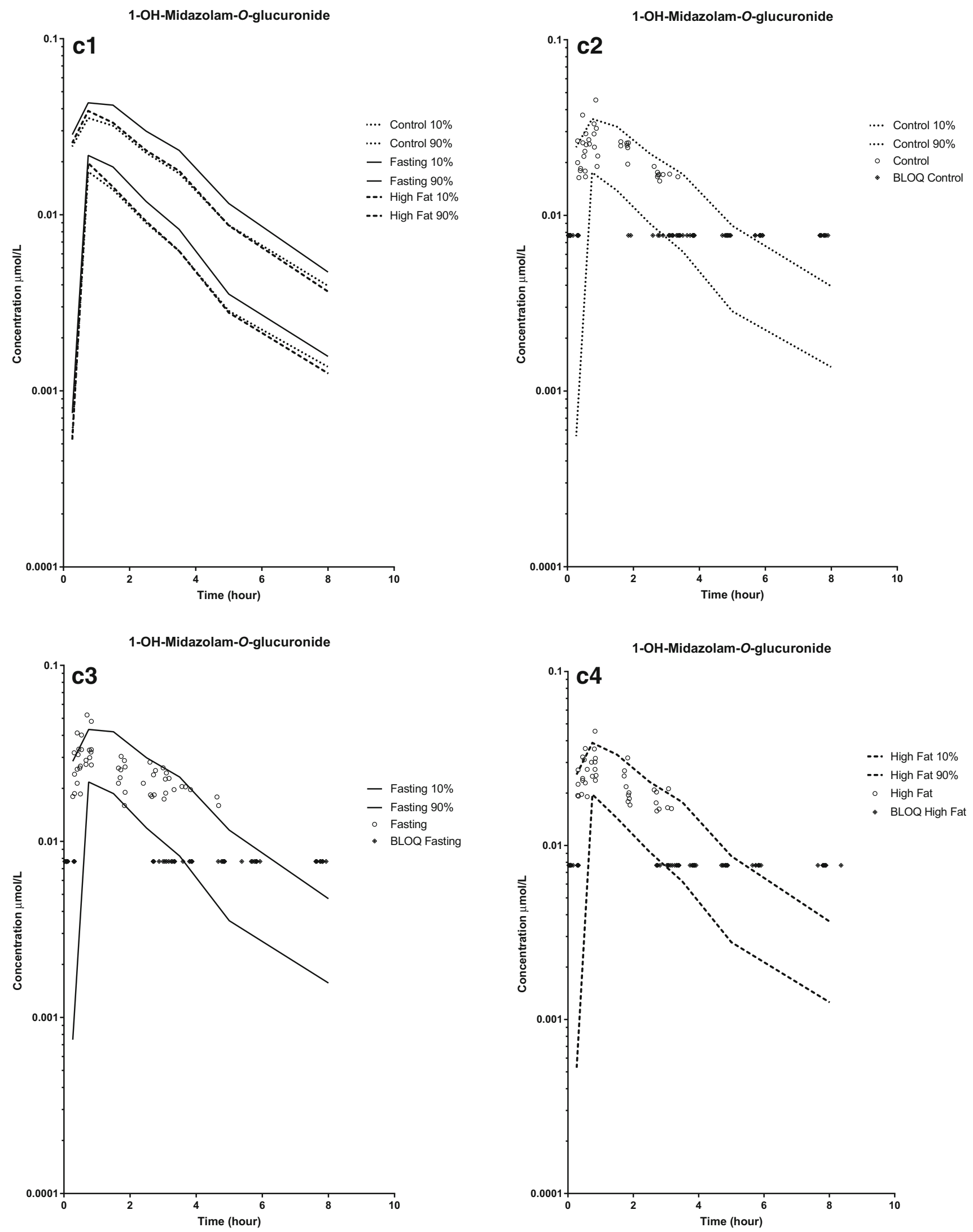

Fig. 2 continued 

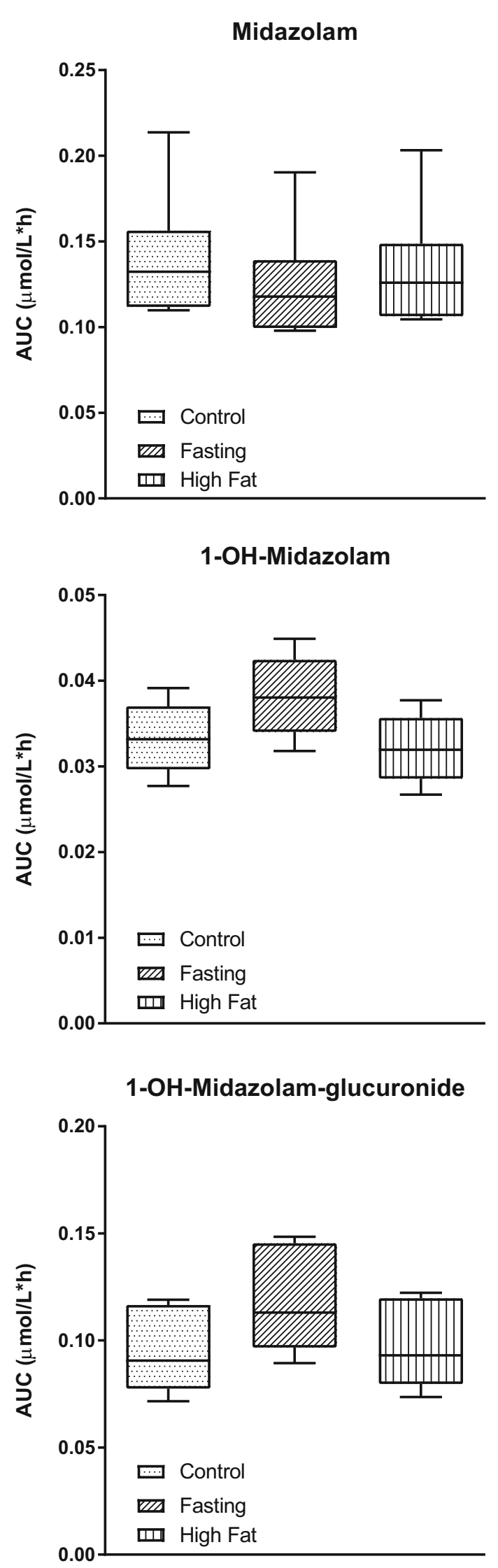

4Fig. 3 Post hoc area under the plasma concentration-time curve (AUC) results of midazolam and metabolites. Box plots represent the control, $36 \mathrm{~h}$ of fasting, and high fat diet interventions [median and range (upper and lower limits)]

new steady state as reflected by the elimination half-life of the enzyme. Since the reported turnover half-lives for CYP3A4 are highly variable ranging from 10 to $140 \mathrm{~h}$, the effects of fasting on enzyme expression are probably not maximal after $36 \mathrm{~h}$ of fasting [32]. For example, maximum induction of CYP3A is reached after 3 days of rifampicin treatment, which is a powerful inducer of CYP3A4 [33]. Although our observations after $36 \mathrm{~h}$ of fasting may appear to be small $(\sim 12 \%)$, this could be an underestimation of the alterations in CYP-mediated drug clearance in subjects or patients who have fasted for a longer period of time.

Since the administered midazolam dose was fixed to $0.015 \mathrm{mg} / \mathrm{kg}$ for each subject and did not differ between the interventions, increased exposure to 1-OH-midazolam after short-term fasting implies either reduced UGT-mediated clearance and/or an increase of the fraction of metabolite formed (Eq. 2). The latter seems unlikely since midazolam is almost completely metabolized to $1-\mathrm{OH}-$ midazolam already. Therefore, our findings indicate that short-term fasting decreases 1-OH-midazolam clearance by reducing UGT enzyme activity.

As for 1-OH-midazolam, the increased exposure to 1-OH-midazolam- $O$-glucuronide implies either reduced clearance and/or an increase of the fraction of metabolite formed (Eq. 3). Since 1-OH-midazolam is metabolized to an $\mathrm{O}$-linked and an $\mathrm{N}$-linked glucuronide, short-term fasting may decrease the formation of the $N$-linked glucuronide, thereby increasing the formation of the $O$-linked glucuronide [16]. Furthermore, because 1-OH-midazolamglucuronide is predominantly excreted unchanged in urine, it could also be possible that fasting-induced changes in renal clearance affect 1-OH-midazolam- $O$-glucuronide clearance. However, short-term fasting did not affect serum creatinine (Table 1). Additional research is recommended to study the effect of short-term fasting on UGT enzyme activity and the different UGT isoenzymes involved in midazolam metabolism (UGT1A4, UGT2B4/2B7). This should include the analysis of both 1-OH-midazolam- $N$ glucuronide (UGT1A4) and 1-OH-midazolam- $O$-glucuronide (UGT2B4/2B7) not only measured in plasma but also in urine.

The results presented in this study are in line with our previous findings that short-term fasting significantly increased mRNA expression of the orthologues of human CYP3A4 in both rats and mice [6, 34]. However, in our previous studies on the effect of short-term fasting in humans, we did not found an effect of fasting on the 
Fig. 4 Goodness-of-fit plots of midazolam and metabolites.

a Midazolam: panels 1-6. b 1hydroxy-midazolam (1-OHmidazolam): panels 1-6. c 1hydroxy-midazolam- $O$ glucuronide (1-OH-midazolam$O$-glucuronide): panels 1-6.

Observed concentrations versus population predicted (PRED) (left panel) and individual predicted (IPRED) (right panel) concentrations. The closed triangles represent

concentrations below the lower limit of quantification (BLOQ). BLOQ concentrations are fixed at $\mathrm{LOQ} / 2$. The solid line is the line of identity. Panels 1 and 2: the open circles represent the data after control. Panels 3 and 4: the closed circles represent the data after the $36 \mathrm{~h}$ of fasting intervention. Panels 5 and 6: the open triangles represent the data after the high fat diet intervention
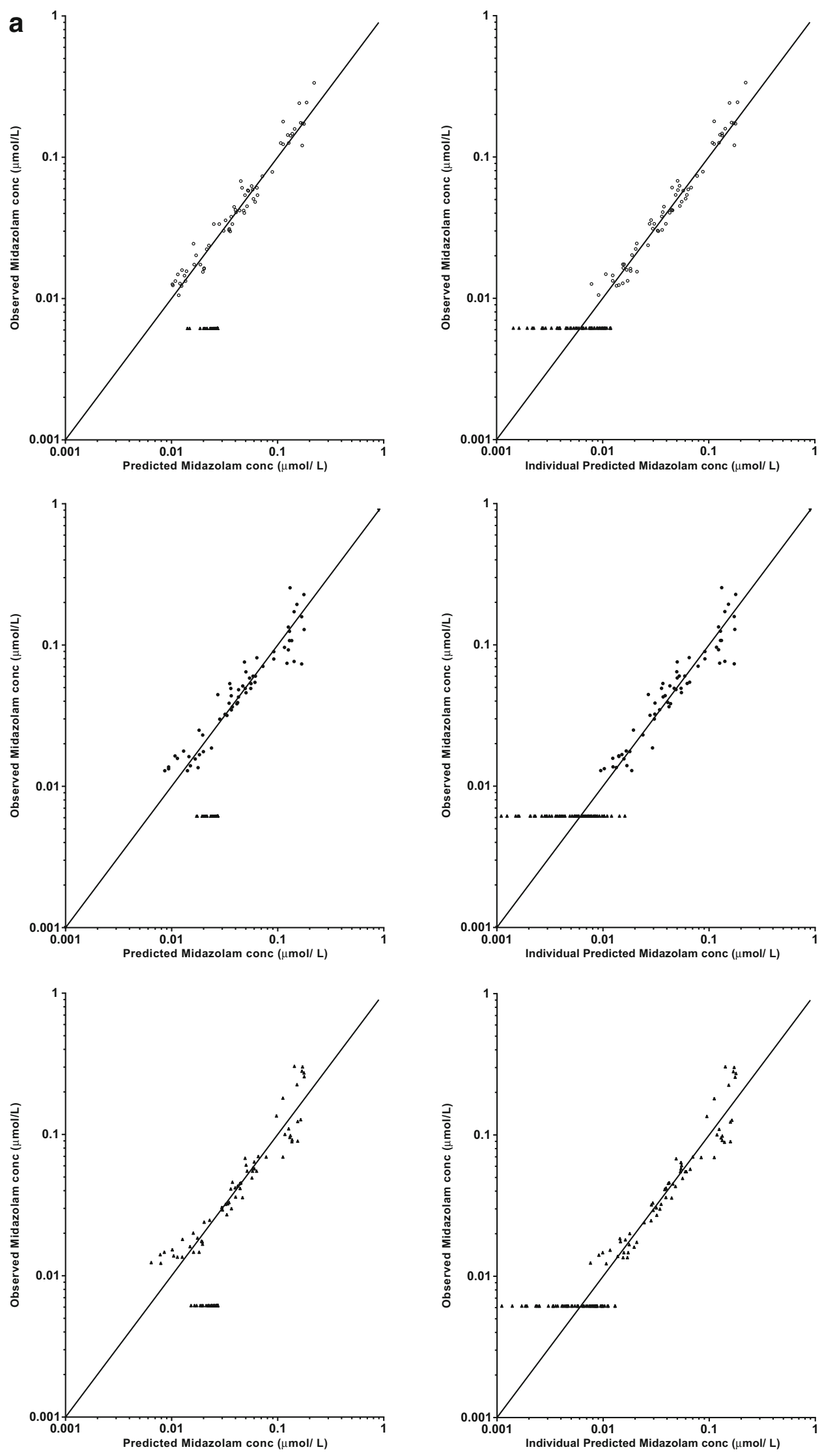

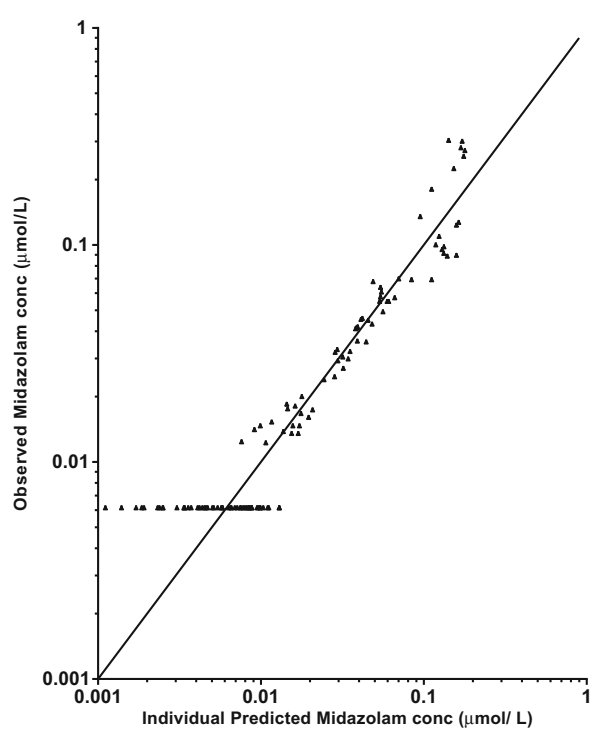


Fig. 4 continued
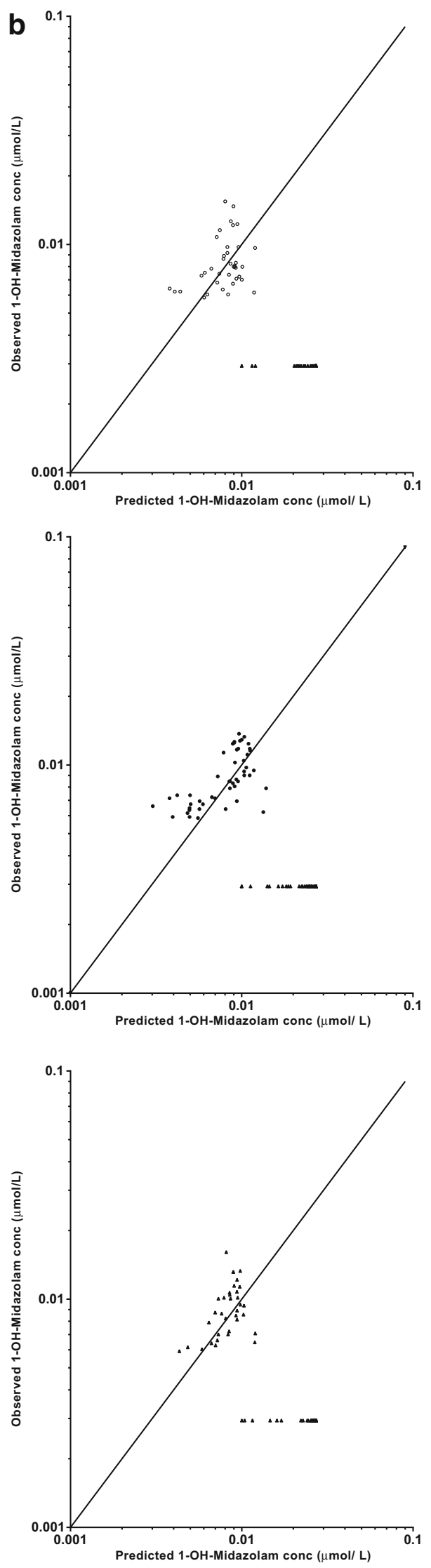
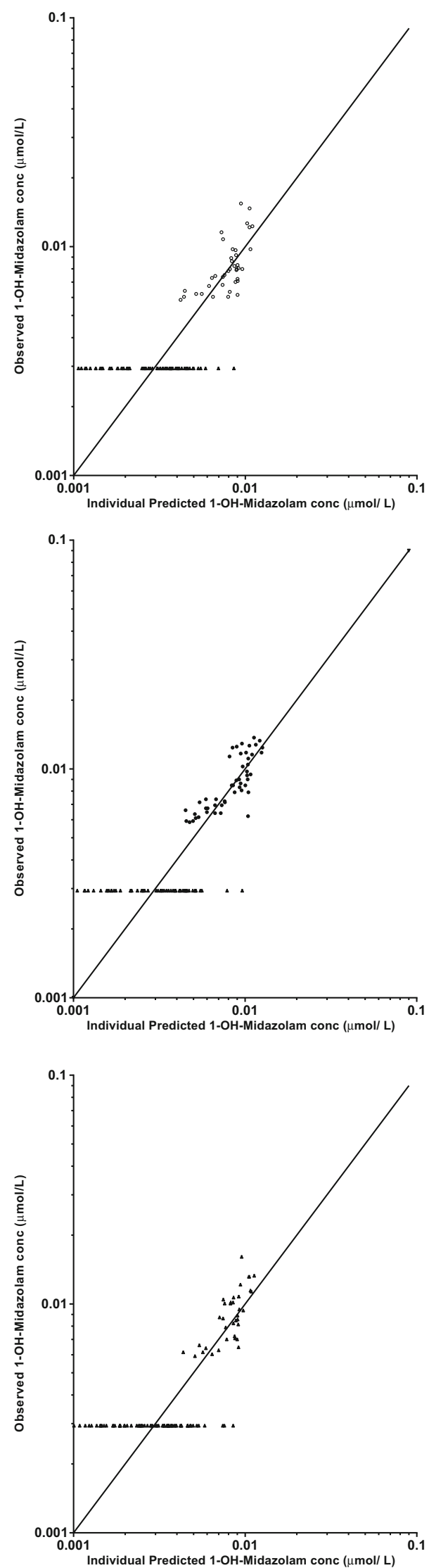
Fig. 4 continued
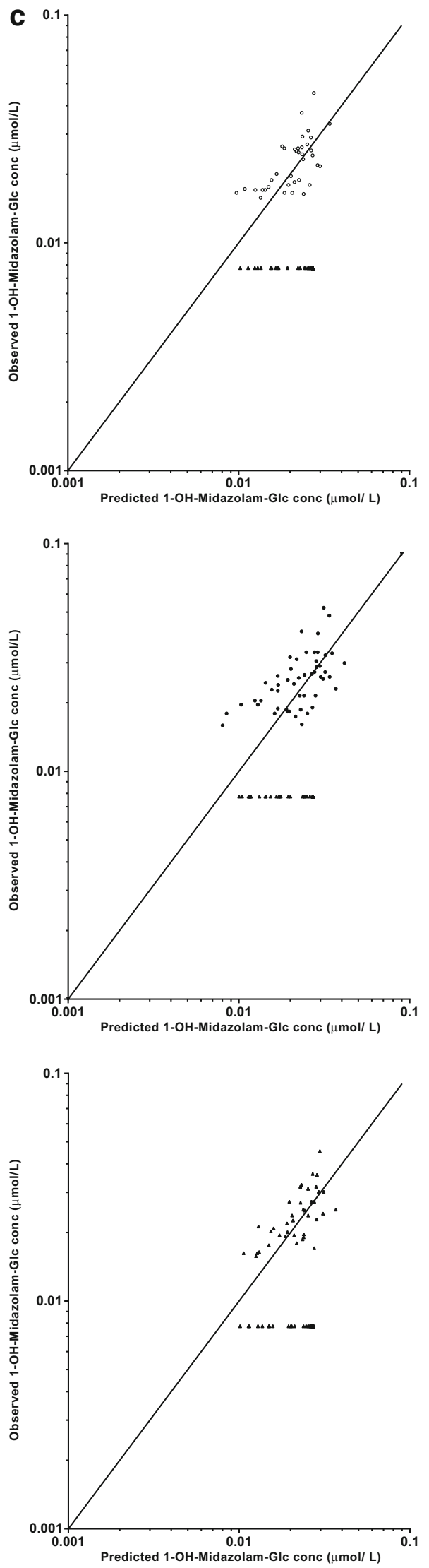
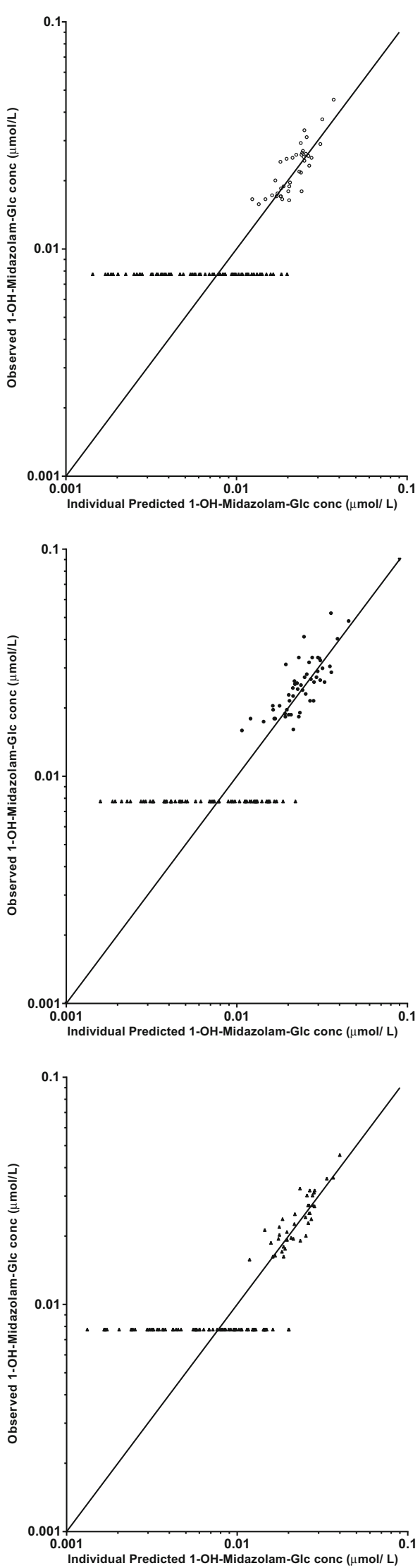
pharmacokinetics of midazolam. We reported that shortterm fasting did not alter oral or systemic clearance of the parent compound midazolam in humans $[6,9]$. This may be explained by the application of a different method to analyze the data in the present study. We observed differences in the time after midazolam administration until concentrations of midazolam and metabolites were below LOQ and, as a consequence, differences in the number of metabolite samples below the lower limit of quantification (BLOQ) between control and the short-term fasting intervention. Instead of excluding the BLOQ data from analysis, which may bias the results, we now applied the M3 method suggested by Beal to account for these data [23]. In the presence of a significant number of BLOQ samples $(\geq 10 \%)$, this method enables a more accurate fit and simulation of the data.

Following intravenous administration of drugs with an intermediate hepatic extraction ratio $\left(E_{\mathrm{H}}=0.3\right.$ to 0.7$)$, such as midazolam $\left(E_{\mathrm{H}}=0.31\right)$, drug clearance can be affected by changes in hepatic blood flow $\left(Q_{\mathrm{H}}\right)$, intrinsic clearance $\left(\mathrm{CL}_{\text {int }}\right.$ ), and protein binding (fraction unbound drug in plasma, $f_{\mathrm{u}}$ ) (Eq. 5) [35, 36]:

$\mathrm{CL}=Q_{\mathrm{H}} \times\left(f_{\mathrm{u}} \times \mathrm{CL}_{\text {int }}\right) /\left(Q_{\mathrm{H}}+f_{\mathrm{u}} \times \mathrm{CL}_{\text {int }}\right)$

We have shown that fasting increases midazolam clearance, but it is unlikely that this is caused by an effect of fasting on $Q_{\mathrm{H}}$ or $f_{\mathrm{u}}$ instead of $\mathrm{CL}_{\text {int }}$. The fraction of unbound midazolam is very low (approximately 2\%) and, therefore, a small increase in $f_{\mathrm{u}}$ due to fasting may significantly alter the results [36]. However, the concentration of drug binding serum albumin was not affected by fasting (Table 1). Furthermore, it is unlikely that fasting would have increased hepatic blood flow $\left(Q_{\mathrm{H}}\right)$ to retrieve the observed effect, since the opposite has been described in the literature $[37,38]$.

A short-term HFD did not alter midazolam clearance after intravenous administration of the drug. This is in agreement with earlier findings of Greenblatt et al., Brill et al., and Van Rongen et al. who reported no difference in clearance values of midazolam between obese and nonobese patients [39-41]. However, this is not consistent with our previous finding that a HFD increases midazolam exposure after oral administration of the drug. After oral administration of midazolam, the observed differences in exposure are a combined effect of an HFD on intrinsic clearance (CYP-enzyme activity), bioavailability and protein binding as described by the well-stirred model of drug metabolism [42]. We may now conclude that a short-term HFD does not alter intrinsic midazolam clearance. Therefore, the previously observed findings of increased midazolam exposure after oral administration are more likely to be caused by differences in bioavailability and/or protein binding.
Seven out of nine subjects were genotyped for 11 different CYP3A4 polymorphisms. For CYP3A4, more than 40 polymorphisms are known [43]. Although subjects were characterized as extensive metabolizers of CYP3A4 (Table 1), it is possible that variability between patients may still be caused by differences in (unknown) genetic profiles. However, the randomized cross-over design in which each subject serves as his own control enabled us to study only the effect of fasting or an HFD within patients instead of a mixture of other factors that may also influence drug metabolism such as genotype, physiologic, and environmental factors. Data on CYP3A4 genotype were retrieved to demonstrate if part of the between-subject variability could be explained by differences in genotype. However, this appeared not to be the case, since all subjects genotyped were extensive metabolizers (genotypically) of CYP3A4. Therefore, other factors than CYP3A4 polymorphisms are likely to cause the relatively large between patient variability (Fig. 3) of midazolam.

\section{Conclusion}

The results found will not be clinically relevant for patients using midazolam. However, since midazolam was administered as a probe to study drug-metabolizing enzyme activity (CYP3A4 and UGT), our findings imply that dosage adjustments of other drugs metabolized by these enzymes could be necessary to improve drug treatment in patients with fasting-related consequences such as weight loss and cachexia. Additional research should especially focus on drugs with a narrow therapeutic window such as immune-modulators (e.g., tacrolimus) and certain drugs used in oncology (e.g., docetaxel, cyclophosphamide, and tyrosine kinase inhibitors such as erlotinib and gefitinib).

Our study provides evidence that short-term fasting differentially alters phase I and II drug-metabolizing enzymes by increasing CYP3A4-mediated but decreasing UGT-mediated midazolam metabolism. Additional research is warranted to study the clinical implications of our findings.

Acknowledgements The authors would like to thank M. Pistorius and N. Frens for their specific contribution to the laboratory analysis of this study.

\section{Compliance with Ethical Standards}

Funding This study did not receive funding.

Conflict of interest The authors, L. A. Lammers, R. Achterbergh, J. A. Romijn, and R. A. A. Mathôt, have no conflict of interest to declare. 
Ethical approval All procedures performed were in accordance with the ethical standards of the institutional research committee. Furthermore, the study was conducted in accordance with the 1964 Helsinki declaration and its later amendments or comparable ethical standards.

Informed consent Informed consent was obtained from all individual participants included in the study.

Open Access This article is distributed under the terms of the Creative Commons Attribution-NonCommercial 4.0 International License (http://creativecommons.org/licenses/by-nc/4.0/), which permits any noncommercial use, distribution, and reproduction in any medium, provided you give appropriate credit to the original author(s) and the source, provide a link to the Creative Commons license, and indicate if changes were made.

\section{References}

1. Ingelman-Sundberg M. Pharmacogenetics: an opportunity for a safer and more efficient pharmacotherapy. J Intern Med. 2001;250(3):186-200.

2. Murray M. Altered CYP expression and function in response to dietary factors: potential roles in disease pathogenesis. Curr Drug Metab. 2006;7(1):67-81.

3. Merrell MD, Cherrington NJ. Drug metabolism alterations in nonalcoholic fatty liver disease. Drug Metab Rev. 2011;43(3):317-34. https://doi.org/10.3109/03602532.2011. 577781 .

4. Longo V, Ingelman-Sundberg M, Amato G, Salvetti A, Gervasi PG. Effect of starvation and chlormethiazole on cytochrome P450s of rat nasal mucosa. Biochem Pharmacol. 2000;59(11):1425-32.

5. Qu W, Rippe RA, Ma J, Scarborough P, Biagini C, Fiedorek FT, et al. Nutritional status modulates rat liver cytochrome P450 arachidonic acid metabolism. Mol Pharmacol. 1998;54(3):504-13.

6. Lammers LA, Achterbergh R, de Vries EM, van Nierop FS, Klumpen HJ, Soeters MR, et al. Short-term fasting alters cytochrome P450-mediated drug metabolism in humans. Drug Metab Dispos. 2015;43(6):819-28. https://doi.org/10.1124/dmd.114.062299.

7. Achterbergh R, Lammers LA, van Nierop S, Klumpen HJ, Soeters MR, Mathot RA, et al. A short-term high fat diet increases exposure to midazolam and omeprazole in healthy subjects. Expert Opin Drug Metab Toxicol. 2016;12(7):715-20. https://doi.org/10.1080/17425255.2016.1192126.

8. Xu J, Kulkarni SR, Li L, Slitt AL. UDP-glucuronosyltransferase expression in mouse liver is increased in obesity- and fastinginduced steatosis. Drug Metab Dispos. 2012;40(2):259-66. https://doi.org/10.1124/dmd.111.039925.

9. Lammers LA, Achterbergh R, van Schaik RH, Romijn JA, Mathot RA. Effect of short-term fasting on systemic cytochrome P450-mediated drug metabolism in healthy subjects: a randomized, controlled, crossover study using a cocktail approach. Clin Pharmacokinet. 2017. https://doi.org/10.1007/s40262-017-05157.

10. Ghose R, Omoluabi O, Gandhi A, Shah P, Strohacker K, Carpenter $\mathrm{KC}$, et al. Role of high-fat diet in regulation of gene expression of drug metabolizing enzymes and transporters. Life Sci. 2011;89(1-2):57-64. https://doi.org/10.1016/j.lfs.2011.05. 005 .

11. Puccinelli E, Gervasi PG, Longo V. Xenobiotic metabolizing cytochrome P450 in pig, a promising animal model. Curr Drug Metab. 2011;12(6):507-25.
12. Osabe M, Sugatani J, Fukuyama T, Ikushiro S, Ikari A, Miwa M. Expression of hepatic UDP-glucuronosyltransferase 1A1 and 1A6 correlated with increased expression of the nuclear constitutive androstane receptor and peroxisome proliferator-activated receptor alpha in male rats fed a high-fat and high-sucrose diet. Drug Metab Dispos. 2008;36(2):294-302. https://doi.org/10. 1124/dmd.107.017731.

13. Miyauchi E, Tachikawa M, Decleves X, Uchida Y, Bouillot JL, Poitou C, et al. Quantitative atlas of cytochrome P450, UDPglucuronosyltransferase, and transporter proteins in jejunum of morbidly obese subjects. Mol Pharm. 2016;13(8):2631-40. https://doi.org/10.1021/acs.molpharmaceut.6b00085.

14. Klieber S, Hugla S, Ngo R, Arabeyre-Fabre C, Meunier V, Sadoun F, et al. Contribution of the $\mathrm{N}$-glucuronidation pathway to the overall in vitro metabolic clearance of midazolam in humans. Drug Metab Dispos. 2008;36(5):851-62. https://doi.org/10.1124/ dmd.107.019539.

15. Vossen M, Sevestre M, Niederalt C, Jang IJ, Willmann S, Edginton AN. Dynamically simulating the interaction of midazolam and the CYP3A4 inhibitor itraconazole using individual coupled whole-body physiologically-based pharmacokinetic (WB-PBPK) models. Theor Biol Med Model. 2007;4:13. https://doi.org/10. 1186/1742-4682-4-13.

16. Zhu B, Bush D, Doss GA, Vincent S, Franklin RB, Xu S. Characterization of $1^{\prime}$-hydroxymidazolam glucuronidation in human liver microsomes. Drug Metab Dispos. 2008;36(2):331-8. https://doi.org/10.1124/dmd.107.017962.

17. Lammers LA, Achterbergh R, Pistorius MC, Bijleveld Y, de Vries EM, Boelen A, et al. Quantitative method for simultaneous analysis of a 5-probe cocktail for cytochrome P450 enzymes. Ther Drug Monit. 2016;38(6):761-8. https://doi.org/10.1097/ FTD.0000000000000338.

18. Foster KJ, Alberti KG, Hinks L, Lloyd B, Postle A, Smythe P, et al. Blood intermediary metabolite and insulin concentrations after an overnight fast: reference ranges for adults, and interrelations. Clin Chem. 1978;24(9):1568-72.

19. Khan AR, Awan FR, Najam SS, Islam M, Siddique T, Zain M. Elevated serum level of human alkaline phosphatase in obesity. J Pak Med Assoc. 2015;65(11):1182-5.

20. Banderas DZ, Escobedo J, Gonzalez E, Liceaga MG, Ramirez JC, Castro MG. gamma-Glutamyl transferase: a marker of nonalcoholic fatty liver disease in patients with the metabolic syndrome. Eur J Gastroenterol Hepatol. 2012;24(7):805-10. https://doi.org/ 10.1097/MEG.0b013e328354044a.

21. Jonsson EN, Karlsson MO. Xpose-an S-PLUS based population pharmacokinetic/pharmacodynamic model building aid for NONMEM. Comput Methods Progr Biomed. 1999;58(1):51-64.

22. Keizer RJ, van Benten M, Beijnen JH, Schellens JH, Huitema AD. Pirana and PCluster: a modeling environment and cluster infrastructure for NONMEM. Comput Methods Progr Biomed. 2011;101(1):72-9. https://doi.org/10.1016/j.cmpb.2010.04.018.

23. Beal SL. Ways to fit a PK model with some data below the quantification limit. $\mathrm{J}$ Pharmacokinet Pharmacodyn. 2001;28(5):481-504.

24. Mould DR, Upton RN. Basic concepts in population modeling, simulation, and model-based drug development-part 2: introduction to pharmacokinetic modeling methods. CPT Pharmacomet Syst Pharmacol. 2013;2:e38. https://doi.org/10.1038/psp. 2013.14.

25. Karlsson MO, Savic RM. Diagnosing model diagnostics. Clin Pharmacol Ther. 2007;82(1):17-20. https://doi.org/10.1038/sj. clpt.6100241.

26. Bijleveld YA, de Haan TR, van der Lee HJ, Groenendaal F, Dijk $\mathrm{PH}$, van Heijst A, et al. Altered gentamicin pharmacokinetics in term neonates undergoing controlled hypothermia. $\mathrm{Br} \mathrm{J}$ Clin 
Pharmacol. 2016;81(6):1067-77. https://doi.org/10.1111/bcp. 12883.

27. Mandema JW, Verotta D, Sheiner LB. Building population pharmacokinetic-pharmacodynamic models. I. Models for covariate effects. J Pharmacokinet Biopharm. 1992;20(5):511-28.

28. Ette EI. Stability and performance of a population pharmacokinetic model. J Clin Pharmacol. 1997;37(6):486-95.

29. Bergstrand M, Hooker AC, Wallin JE, Karlsson MO. Predictioncorrected visual predictive checks for diagnosing nonlinear mixed-effects models. AAPS J. 2011;13(2):143-51. https://doi. org/10.1208/s12248-011-9255-z.

30. Lindbom L, Pihlgren P, Jonsson EN. PsN-Toolkit-a collection of computer intensive statistical methods for non-linear mixed effect modeling using NONMEM. Comput Methods Progr Biomed. 2005;79(3):241-57. https://doi.org/10.1016/j.cmpb. 2005.04.005.

31. EMA. Guideline for the investigation of drug interactions. London: EMA; 2012

32. Yang J, Liao M, Shou M, Jamei M, Yeo KR, Tucker GT, et al. Cytochrome p450 turnover: regulation of synthesis and degradation, methods for determining rates, and implications for the prediction of drug interactions. Curr Drug Metab. 2008;9(5):384-94.

33. Tran JQ, Kovacs SJ, McIntosh TS, Davis HM, Martin DE. Morning spot and 24-hour urinary 6 beta-hydroxycortisol to cortisol ratios: intraindividual variability and correlation under basal conditions and conditions of CYP 3A4 induction. J Clin Pharmacol. 1999;39(5):487-94.

34. de Vries EM, Lammers LA, Achterbergh R, Klumpen HJ, Mathot RA, Boelen A, et al. Fasting-induced changes in hepatic P450 mediated drug metabolism are largely independent of the constitutive androstane receptor CAR. PLoS One. 2016;11(7):e0159552. https://doi.org/10.1371/journal.pone.
35. Verbeeck RK. Pharmacokinetics and dosage adjustment in patients with hepatic dysfunction. Eur J Clin Pharmacol. 2008;64(12):1147-61. https://doi.org/10.1007/s00228-008-0553-z.

36. Truven Health Analytics Inc. Micromedex solutions-drug monographs [database on the Internet]. 2014. https://www. micromedexsolutions.com. Accessed: Mar 2014.

37. Lomax MA, Baird GD. Blood flow and nutrient exchange across the liver and gut of the dairy cow. Effects of lactation and fasting. Br J Nutr. 1983;49(3):481-96.

38. Eipel C, Abshagen K, Vollmar B. Regulation of hepatic blood flow: the hepatic arterial buffer response revisited. World $\mathrm{J}$ Gastroenterol. 2010;16(48):6046-57.

39. Greenblatt DJ, Abernethy DR, Locniskar A, Harmatz JS, Limjuco RA, Shader RI. Effect of age, gender, and obesity on midazolam kinetics. Anesthesiology. 1984;61(1):27-35.

40. Brill MJ, van Rongen A, van Dongen EP, van Ramshorst B, Hazebroek EJ, Darwich AS, et al. The pharmacokinetics of the CYP3A substrate midazolam in morbidly obese patients before and one year after bariatric surgery. Pharm Res. 2015;32(12):3927-36. https://doi.org/10.1007/s11095-015-17529.

41. van Rongen A, Vaughns JD, Moorthy GS, Barrett JS, Knibbe CA, van den Anker JN. Population pharmacokinetics of midazolam and its metabolites in overweight and obese adolescents. Br J Clin Pharmacol. 2015;80(5):1185-96. https://doi.org/10.1111/bcp. 12693.

42. Benet LZ, Hoener BA. Changes in plasma protein binding have little clinical relevance. Clin Pharmacol Ther 2002;71(3):115-21. https://doi.org/10.1067/mcp.2002.121829.

43. Lamba JK, Lin YS, Thummel K, Daly A, Watkins PB, Strom S, et al. Common allelic variants of cytochrome P4503A4 and their prevalence in different populations. Pharmacogenetics. 2002;12(2):121-32. 